\title{
Quantitative HPLC-ICP-MS analysis of antimony redox speciation in complex sample matrices: new insights into the Sb-chemistry causing poor chromatographic recoveries
}

Hansen, Claus; Schmidt, Bjørn; Larsen, Erik Huusfeldt; Gammelgaard, Bente; Stürup, Stefan; Hansen, Helle Rüsz

\section{Published in:}

Analyst

Link to article, DOI:

10.1039/c0an00796j

Publication date:

2011

Document Version

Publisher's PDF, also known as Version of record

Link back to DTU Orbit

\section{Citation (APA):}

Hansen, C., Schmidt, B., Larsen, E. H., Gammelgaard, B., Stürup, S., \& Hansen, H. R. (2011). Quantitative HPLC-ICP-MS analysis of antimony redox speciation in complex sample matrices: new insights into the Sbchemistry causing poor chromatographic recoveries. Analyst, 136(5), 996-1002.

https://doi.org/10.1039/c0an00796j

\section{General rights}

Copyright and moral rights for the publications made accessible in the public portal are retained by the authors and/or other copyright owners and it is a condition of accessing publications that users recognise and abide by the legal requirements associated with these rights.

- Users may download and print one copy of any publication from the public portal for the purpose of private study or research.

- You may not further distribute the material or use it for any profit-making activity or commercial gain

- You may freely distribute the URL identifying the publication in the public portal 


\title{
Quantitative HPLC-ICP-MS analysis of antimony redox speciation in complex sample matrices: new insights into the Sb-chemistry causing poor chromatographic recoveries $\dagger$
}

\author{
Claus Hansen, ${ }^{* a}$ Bjørn Schmidt, ${ }^{b}$ Erik H. Larsen, ${ }^{b}$ Bente Gammelgaard, ${ }^{a}$ Stefan Stürup ${ }^{a}$ \\ and Helle Rüsz Hansen ${ }^{a}$
}

Received 13th October 2010, Accepted 22nd November 2010

DOI: 10.1039/c0an00796j

In solution antimony exists either in the pentavalent or trivalent oxidation state. $\mathrm{As} \mathrm{Sb}$ (III) is more toxic than $\mathrm{Sb}(\mathrm{v})$, it is important to be able to perform a quantitative speciation analysis of Sb's oxidation state. The most commonly applied chromatographic methods used for this redox speciation analysis do, however, often show a low chromatographic $\mathrm{Sb}$ recovery when samples of environmental or biological origin are analysed. In this study we explored basal chemistry of antimony and found that formation of macromolecules, presumably oligomeric and polymeric $\mathrm{Sb}(\mathrm{v})$ species, is the primary cause of low chromatographic recoveries. A combination of HPLC-ICP-MS, AFFF-ICP-MS and spinfiltration was applied for analysis of model compounds and biological samples. Quantitative chromatographic $\mathrm{Sb}$ redox speciation analysis was possible by acidic hydrolysis of the antimony polymers prior to analysis. Sample treatment procedures were studied and the optimum solution was acidic hydrolysis by $1 \mathrm{M} \mathrm{HCl}$ in the presence of chelating ligands (EDTA, citrate), which stabilise the trivalent oxidation state of $\mathrm{Sb}$.

\section{Introduction}

In aqueous solution, antimony exists either in the pentavalent or trivalent oxidation state. $\mathrm{Sb}(\mathrm{III})$ is considered more toxic than $\mathrm{Sb}(\mathrm{v}) ;{ }^{1}$ therefore it is important to be able to perform a complete quantitative redox speciation analysis. The determination of $\mathrm{Sb}(\mathrm{III})$ and $\mathrm{Sb}(\mathrm{v})$ in aqueous solution is most commonly performed by separation by anion-exchange chromatography (AEC) followed by element specific detection. ${ }^{2,3}$ Separation of aqueous $\mathrm{Sb}(\mathrm{v})$ and $\mathrm{Sb}(\mathrm{III})$ is typically achieved on a strong AEC column, using a mobile phase of $\mathrm{pH} 4.0-5.5$ containing chelating ligands, such as EDTA, phthalic acid or tartrate.

The importance of complexing ligands in the mobile phase for AEC was established by Lintschinger et al., ${ }^{4}$ who also showed that adding a strong competing anion, e.g. phthalate, to the EDTA mobile phase improved the chromatographic system by shifting the $\mathrm{Sb}$ (III) peak to a shorter retention time and improving

${ }^{a}$ University of Copenhagen, Department of Pharmaceutics and Analytical Chemistry, Universitetsparken 2, DK-2100 Copenhagen Ø, Denmark. E-mail: clha@farma.ku.dk; Fax: +45 3533 6010;Tel: +45 35336420

${ }^{b}$ Technical University of Denmark, National Food Institute, Mørkhøj Bygade 19, DK-2860 Soborg, Denmark

$\dagger$ Electronic supplementary information (ESI) available: HPLC-ICP-MS chromatograms showing the effect of acid pretreatment on Pentostam ${ }^{\mathrm{TM}}$, adenosine-Sb(v) and cell extract when using the mobile phase of $20 \mathrm{mM}$ EDTA and $2 \mathrm{mM}$ phthalic acid (Figure Si, Sii and Siv, resp.), and on adenosine-Sb(v) when using the $100 \mathrm{mM}$ citrate mobile phase (Figure Siii). See DOI: 10.1039/c0an00796j its symmetry. A complexing mobile phase serves to preserve the trivalent oxidation state of $\mathrm{Sb}$ during the chromatographic separation, as $\mathrm{Sb}(\mathrm{III})$ easily oxidizes to $\mathrm{Sb}(\mathrm{v})$ in aqueous solutions. ${ }^{5}$ Moreover, in most cases $\mathrm{Sb}(\mathrm{III})$ is irreversibly retained on the AEC columns when chelators are not present in the mobile phase. ${ }^{4,6}$ It should be noted that $\mathrm{Sb}$ (III) species also have been reported to be retained irreversibly on reversed phase columns. ${ }^{7}$

As the AEC method using a combination of EDTA and phthalic acid in the mobile phase appears to be the most successful approach for determination of $\mathrm{Sb}$ oxidation state so far, it has been extensively applied. ${ }^{3} \mathrm{Sb}$ (III)-citrate, $\mathrm{Sb}$ (III)tartrate and $\mathrm{SbCl}_{3}$ all elute at the same retention time due to the mobile phase's conversion of all complexes into an $\mathrm{Sb}$ (III)-EDTA complex. ${ }^{4,8}$ Lintchinger et al. pointed out the importance of this effect when performing redox speciation analysis on real world samples, in order to avoid $\mathrm{Sb}$ (III) hiding in peaks of unknown identity. ${ }^{4}$ However, EDTA does not chelate $\mathrm{Sb}(\mathrm{v})$, as $\mathrm{Sb}(\mathrm{v})$-citrate and $\mathrm{Sb}(\mathrm{OH})_{6}{ }^{-}$elute at different retention times (as demonstrated in Fig. 1, mobile phase A) at the applied concentrations and $\mathrm{pH}$ values. ${ }^{8,9}$ Hence, the lacking ability to convert $\mathrm{Sb}(\mathrm{v})$ complexes into one common complex partly explains the numerous reports of unidentified peaks even in studies where the EDTA-phthalic acid mobile phase was used ${ }^{\mathbf{8}, 10-12}$ For the purpose of oxidation state determination, the elution of various $\mathrm{Sb}$ complexes is a limitation. Likewise it has been pointed out that the proximity of the $\mathrm{Sb}(\mathrm{OH})_{6}{ }^{-}$peak to the void elution makes identification of this $\mathrm{Sb}$ species less reliable. ${ }^{13}$ 

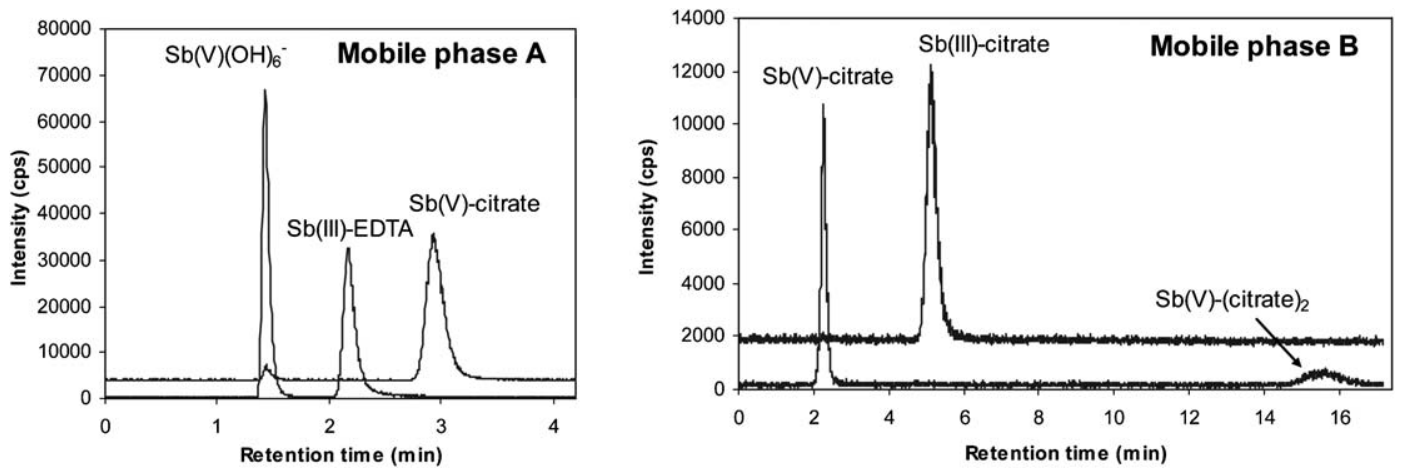

Fig. 1 Comparison of HPLC-ICP-MS chromatograms achieved with mobile phase A (20 mM EDTA, $2 \mathrm{mM}$ phthalic acid, pH 4.5) and B (100 mM citrate, $\mathrm{pH} 4.5$ ). The most likely identity of the eluted species is stated. The void elution is approx. at 1.3 minutes (determined by injecting $\left.\mathrm{Li}^{+}\right)$; i.e. $13 \mathrm{~s}$ prior to the $\mathrm{Sb}(\mathrm{OH})_{6}{ }^{-}$peak with mobile phase A. In mobile phase A, Sb(III) elutes as the EDTA complex regardless whether $\mathrm{SbCl}{ }_{3}, \mathrm{Sb}(\mathrm{III})$-tartrate or $\mathrm{Sb}(\mathrm{III})$-citrate is injected, whereas $\mathrm{Sb}(\mathrm{v})(\mathrm{OH})_{6}{ }^{-}$and $\mathrm{Sb}(\mathrm{v})$-citrate elute at different retention times. In mobile phase B both oxidation states elute as citrate complexes.

This was clearly illustrated by Hansen and Pergantis in a study where the peak eluting at the retention time of $\mathrm{Sb}(\mathrm{OH})_{6}{ }^{-}$upon further analysis revealed to consist of not less than five different Sb species. ${ }^{6}$

The AEC method based on the EDTA-phthalic acid mobile phase typically gives an $\mathrm{Sb}$ recovery of $100 \%$ when applied for analysis of water samples or standard solutions. However, it is notable that the chromatographic recovery is often not complete when analysing extracts of biological and environmental samples. Krachler and Emons reported a chromatographic recovery of $51-78 \%$ when analysing $\mathrm{Sb}$ in urine. ${ }^{14}$ Hansen and Pergantis had a recovery of $73 \%$ for $\mathrm{Sb}(\mathrm{v})$ spiked to yoghurt. ${ }^{6}$ Zheng et al. calculated a recovery of $60 \%$ when analysing aqueous extracts of particulate matter; ${ }^{9}$ in a recent study Canepari et al. had recoveries of $10-70 \%$ for similar extracts and attributed it to the presence of antimony nanoparticles. ${ }^{10}$ When de Gregori et al. speciated $\mathrm{Sb}$ in different marine algae, the recoveries varied between 18 and $93 \%{ }^{15}$ In most studies, however, the chromatographic recovery is not reported.

$\mathrm{Sb}(\mathrm{v})$ can chelate to $\alpha$-hydroxy carboxylic acids ${ }^{16}$ and to vicinal hydroxy groups; ${ }^{17,18}$ such multidentate bindings seem to explain the polymeric nature of the $\mathrm{Sb}(\mathrm{v})$ based drug sodium stibogluconate (Pentostam ${ }^{\mathrm{TM}}$ ). ${ }^{19}$ Likewise, the drug meglumine antimonate is oligomeric due to chelation by vicinal hydroxy functions. $^{20}$ Several types of organic $\mathrm{Sb}(\mathrm{v})$ polymers are described where $\mathrm{Sb}$ is bound via oxygen atoms in a non-chelate fashion, e.g. as ether or ester bonds. ${ }^{21}$ Carraher and Blaxall reported that the synthesis of $\mathrm{Sb}(\mathrm{v})$-polyesters from alkylated $\mathrm{Sb}$ halides and organic diacids happens rapidly already at room temperature. ${ }^{22}$ Also $\mathrm{Sb}(\mathrm{III})$ polymer formation has been described with organic polyhydroxy compounds. ${ }^{23} \mathrm{Sb}(\mathrm{v})$ is a well known catalyst of esterification ${ }^{24}$ and an initiator of cationic polymerisation. ${ }^{25} \mathrm{Sb}(\mathrm{III})$ is extensively used as a polycondensation catalyst in the production of poly(ethylene terephthalate), where it promotes esterification and transesterification. ${ }^{26}$ Thus, antimony both forms polymers with organic molecules and catalyses polymerisation reactions.

The association between antimony and polymers made us hypothesise that the widespread problems with low chromatographic recoveries of $\mathrm{Sb}$ in extracts of biological samples are due to incorporation of $\mathrm{Sb}$ in polymers, which do not elute from the High Performance Liquid Chromatography (HPLC) columns. The aims of this study were to: (1) document the formation of polymers between $\mathrm{Sb}$ and biological molecules in dilute solutions ( $\mu \mathrm{M}$ level), (2) document their corruption of chromatographic HPLC recoveries and (3) develop a procedure for liberating the $\mathrm{Sb}$ from the polymers in order to make $\mathrm{Sb}$ redox speciation analysis possible. As a simple model of a biological sample, a solution of $\mathrm{Sb}(\mathrm{v})$ incubated with an excess of ascorbic acid was used. Ascorbic acid is known to oxidise to a variety of components with alcohol, aldehyde, ketone and carboxylic acid functional groups. ${ }^{27}$ Thus, if $\mathrm{Sb}$ is capable of forming polymers with molecules with multiple $-\mathrm{OH}$ functional groups in aqueous solutions at low temperatures, polymers are expected in this solution. Ascorbic acid is also able to reduce $\mathrm{Sb}(\mathrm{v})$ to $\mathrm{Sb}(\mathrm{III}),{ }^{28}$ so both oxidation states will be available for polymerisation reactions. Other samples either known to contain oligomeric Sb species (Pentostam) or to have $\mathrm{Sb}(\mathrm{v})$ chelates $(\mathrm{Sb}(\mathrm{v})$-adenosine and $\mathrm{Sb}(\mathrm{v})$-citrate) were also analysed. Finally, the optimised procedure for $\mathrm{Sb}$ redox speciation analysis was tested on extracts of leukocyte cells incubated with $\mathrm{Sb}$ (the experiments are summarised in Table 1).

\section{Experimental}

\section{Chemicals and reagents}

Antimony(III) chloride, citric acid monohydrate, acetic acid, ascorbic acid, ammonia (28\%), dimethyl sulfoxide (DMSO) and sodium dodecyl sulfate were from Merck (Darmstadt, Germany); potassium hexahydroxoantimonate, phthalic acid, diammonium EDTA and tetraethylammonium hydroxide $(40 \%)$ were from Fluka (Buchs, Switzerland); ammonium formate and ammonium acetate were from Riedel-de Haën (Seelze, Germany); diammonium citrate, adenosine ( $\geq 99 \%$ ) and formic acid were from Sigma-Aldrich (Steinheim, Germany); hydrochloric acid $(30 \%)$ was form VWR International (Fontenay-sous-Bois, France); and sodium stibogluconate (Pentostam ${ }^{\mathrm{TM}}$ ) was from GlaxoSmithKline (Barnard Castle, UK). The water used throughout the study was Millipore deionised water (18.2 M $\Omega$ 
Table 1 Summary of chromatographic experiments. Concentrations: HCl 1 M; EDTA $30 \mathrm{mM}$; citric acid (citr.a.) $100 \mathrm{mM}$. Mobile phase A (mp A) 20 $\mathrm{mM}$ EDTA and $2 \mathrm{mM}$ phthalic acid, mobile phase B (mp B) $100 \mathrm{mM}$ citric acid; both at $\mathrm{pH} 4.5$

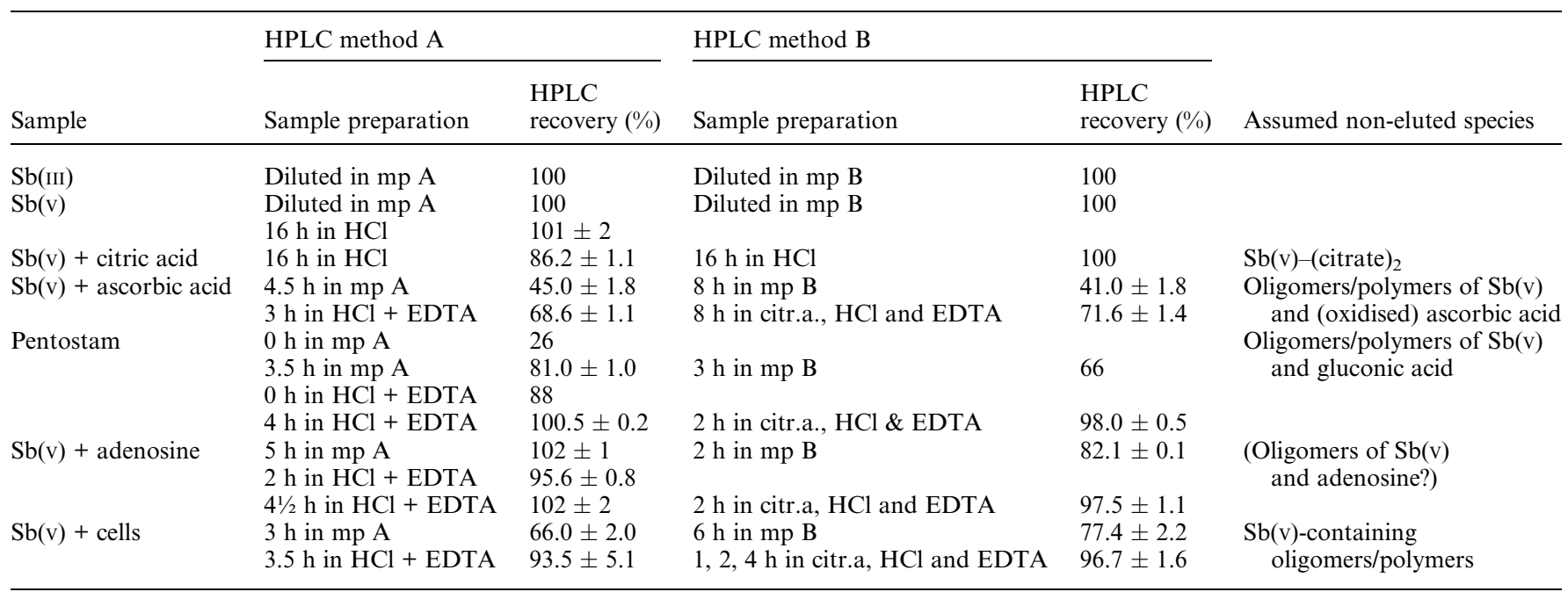

$\mathrm{cm}$ ) from a Milli-Q Plus Ultra-pure water system from Millipore (Bedford, USA). All reagents were of analytical grade.

Mobile phases: (A) a mixture of $20 \mathrm{mM}\left(\mathrm{NH}_{4}\right)_{2}$ EDTA and 2 $\mathrm{mM}$ phthalic acid or (B) $100 \mathrm{mM}$ citric acid, both of $\mathrm{pH} 4.5$ (adjusted with ammonia).

$\mathrm{Sb}(\mathrm{v})$ stock solution $(12.0 \mathrm{mM})$ was prepared by dissolving potassium hexahydroxoantimonate in water. A $\mathrm{Sb}$ (III) stock solution $\left(50.0 \mathrm{mM}\right.$ ) was prepared by dissolving $\mathrm{SbCl}_{3}$ in DMSO. Ascorbic acid-Sb mixtures of $10 \mu \mathrm{M} \mathrm{KSb}(\mathrm{OH})_{6}$ or $\mathrm{SbCl}_{3}$ and $100 \mathrm{mM}$ ascorbic acid were prepared in a $180 \mathrm{mM}$ ammonium acetate buffer at $\mathrm{pH} 5.0$ and incubated for five days at $37{ }^{\circ} \mathrm{C}$ following at least eight days incubation at room temperature. No precipitation or opaqueness of the solution, which would indicate the presence of particles, was observed. Adenosine-Sb(v) mixture of $10 \mu \mathrm{M} \mathrm{KSb}(\mathrm{OH})_{6}$ and $10 \mathrm{mM}$ adenosine was prepared in water; the mixture was allowed to stand for at least $1 \frac{1}{2} \mathrm{~h}$ prior to use to allow $\mathrm{Sb}(\mathrm{v})$-adenosine complexes to form. For sample pretreatment, citrate was used as a $4 \mathrm{M}$ stock solution, $\left(\mathrm{NH}_{4}\right)_{2}$ EDTA as a $300 \mathrm{mM}$ stock solution, and $\left(\mathrm{NH}_{4}\right)_{2}-$ citrate as a $2.67 \mathrm{M}$ stock solution. The acidic sample pretreatment was made by adding $30 \% \mathrm{HCl}$ to a final concentration of 1 $\mathrm{M}$, together with EDTA stock solution to $30 \mathrm{mM}$ and where appropriate, citric acid stock solution to $100 \mathrm{mM}$. The amount of sample was chosen so the $\mathrm{Sb}$ concentration in the pretreatment mixtures was $2 \mu \mathrm{M}$, except from the cell extract where it was 665 $\mathrm{nM}$. The pretreatment was performed for minimum $2 \mathrm{~h}$ unless otherwise stated. Neutralisation was best performed with the $\left(\mathrm{NH}_{4}\right)_{2}$-citrate stock solution. Non-acid treated samples were prepared in concentrations of $500 \mathrm{nM}$. Of the samples containing $1 \mathrm{M} \mathrm{HCl}, 2.5 \mu \mathrm{l}$ were injected for HPLC analysis; for other samples $10 \mu \mathrm{l}$ were injected.

\section{Cell cultivation}

Leukocyte cell extracts were prepared from a human leukocyte cell line (ACC 124), cultured as previously described. ${ }^{29}$ The cells were seeded at 0.15 millions per $\mathrm{ml}$ in medium with Pentostam added (to $10 \mathrm{mg} \mathrm{Sb}$ per litre). After 4 days the cells were harvested by centrifugation, washed twice by resuspension in Hank's buffered salt solution (Invitrogen, Paisley, UK), resuspended in $50 \mu \mathrm{l}$ water, lysed with $100 \mu \mathrm{l} \% \mathrm{w} / \mathrm{v}$ sodium dodecyl sulfate and then frozen. The extract was filtered through a $0.45 \mu \mathrm{m}$ syringe filter prior to use.

\section{Ultrafiltration}

Ultrafiltration of Pentostam, the ascorbic acid-Sb(v) mixture and $\mathrm{KSb}(\mathrm{OH})_{6}$ solution was performed in spin filters (Vivaspin 500, Sartorius Stedim Biotech, Göttingen, Germany) with a 3 kDa molecular weight cut-off membrane (polyethersulfone). The $\mathrm{Sb}$ solutions were diluted to $1 \mu \mathrm{M}$ in $100 \mathrm{mM}$ ammonium formate, $\mathrm{pH} 3.5$, prior to filtration. The filters were centrifuged at $14100 \times g$ for 8 minutes. For total $\mathrm{Sb}$ mass balance determination the amount of sample applied, the amount of filtrate, and the amount of the retained solution were determined by weight.

\section{Instrumentation}

HPLC-ICP-MS. A Hamilton PRP-X100 AEC column $(150 \times$ $4.1 \mathrm{~mm} ; 5 \mu \mathrm{m}$; Hamilton Company, Reno, NV, USA) with a guard column was used in combination with an Agilent 1100 HPLC system with an autosampler (Agilent Technologies, Santa

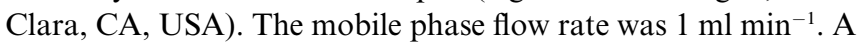
PE-SCIEX ELAN 6000 Inductively Coupled Plasma-Mass Spectrometer (ICP-MS) (Perkin-Elmer, Norwalk, CT, USA) with a $\mathrm{PC}^{3}$ cyclonic spray chamber (Elemental Scientific Inc., Omaha, NE, USA) was used with a MicroMist glass concentric nebulizer (Glass Expansion, Romainmôiter, Switzerland). Lens voltage, nebuliser gas flow and $\mathrm{rf}$ power were optimised on a daily basis. Both antimony isotopes, ${ }^{121} \mathrm{Sb}$ and ${ }^{123} \mathrm{Sb}$, were measured. Data analysis was performed on a TotalChrom workstation (Perkin-Elmer).

AFFF-MALS/DLS-ICP-MS. Asymmetrical Flow Field-Flow Fractionation (AFFF) coupled with Multi-Angle Light Scattering (MALS)-/Dynamic Light Scattering (DLS)- and ICP-MS was carried out using an Eclipse 3 AFFF system equipped with a Dawn HELEOS MALS/DLS detector (Wyatt Technology 
Europe GmbH, Dernbach, Germany) in combination with an Agilent 7500ce ICP-MS system (Agilent Technologies). The injection of samples and delivery of carrier liquid for the AFFF system were carried out using an Agilent 1200 HPLC pump and autosampler system. The size of the detected complexes was estimated with the simulation software Eclipse Chromatogram (Release 1.0.4; Wyatt Technology Europe) using measured retention times of detected $\mathrm{Sb}$ complexes, AFFF flow rate settings, and separation channel dimensions as input variables. During elution the detector flow was set to $0.5 \mathrm{ml} \mathrm{min}^{-1}$ and the

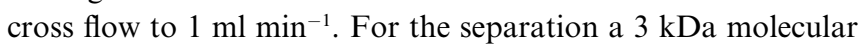
weight cut-off polyethersulfone bottom membrane and a spacer thickness of $350 \mu \mathrm{m}$ was used. The channel length was $152 \mathrm{~mm}$, the channel width $21.5 \mathrm{~mm}$ at the injection site and $3 \mathrm{~mm}$ at the channel exit. The membrane moisture expansion was determined to be $145 \mu \mathrm{m}$ using the retention time and measured Stokes diameter for a polystyrene nanosphere with a known size (Thermo Fisher Scientific, Fremont, CA, USA) using the same flow conditions as for the Sb samples. These values were used as input variables for the simulation of particle size of the $\mathrm{Sb}$ (III) and $\mathrm{Sb}(\mathrm{v})$ complexes.

\section{Results and discussion}

\section{Method optimisation}

An obvious approach for depolymerisation of potential Sbcontaining polymers is acid hydrolysis. Treatment with $\mathrm{HCl}$ has previously been used in sample preparation prior to potentiometric speciation analysis of meglumine antimonate, so that $\mathrm{Sb}$ could be "released in the solution"; ${ }^{30}$ the role of $\mathrm{HCl}$ may likely have been to hydrolyse the previously mentioned oligomers. Hence it seemed promising as a sample treatment procedure prior to chromatography as well. Inclusion of a strong chelating agent such as citric acid in the hydrolysis mixture to bind $\mathrm{Sb}$ should promote the depolymerisation process, shifting the chemical equilibrium in favour of depolymerisation. This strategy was investigated further; however, the initial experiments of treating $\mathrm{Sb}(\mathrm{v})$ solutions with $\mathrm{HCl}$ together with citric acid showed an unexpected low chromatographic recovery, indicating the need for change in the chromatographic procedure. A sample of the $\mathrm{Sb}(\mathrm{v})$ standard incubated with $1 \mathrm{M} \mathrm{HCl}$ and $100 \mathrm{mM}$ citric acid overnight had a chromatographic recovery of only $86.2( \pm 1.1) \%$ when analysed by HPLC-ICP-MS using a mobile phase of $20 \mathrm{mM}$ EDTA and $2 \mathrm{mM}$ phthalic acid, pH 4.5 (mobile phase A). A control sample incubated without citric acid had a recovery of $101( \pm 2) \%$. The reason for this observation became obvious when shifting to a mobile phase of very high eluting strength; $100 \mathrm{mM}$ citric acid at $\mathrm{pH} 4.5$ (mobile phase B). In this mobile phase, the $\mathrm{Sb}(\mathrm{v})$ treated with $\mathrm{HCl}$ and citric acid eluted as two peaks: one at 2.2 minutes and a minor one at 15.3 minutes (Fig. 1, mobile phase B), together providing full recovery. The distribution of $\mathrm{Sb}(\mathrm{v})$ between the peaks when using mobile phase $\mathrm{B}$ proved time and $\mathrm{pH}$ dependent. If $\mathrm{Sb}(\mathrm{v})$ was freshly diluted in the mobile phase prior to injection, no second peak was observed, but with time the peak accounted for up to $4 \%$ of the $\mathrm{Sb}$. At lower $\mathrm{pH}$ values the fraction increased further; for an $\mathrm{Sb}(\mathrm{v})$ sample prepared in $100 \mathrm{mM}$ citrate at $\mathrm{pH} 0$, about $20 \%$ eventually eluted in the second peak. The occurrence of two peaks can be explained by the formation of two different citrate complexes. A likely explanation is that the first peak is a $1: 1 \mathrm{Sb}(\mathrm{v})$-citrate complex, and that the second, slower formed peak is a $1: 2$ complex (both complexes are known to exist ${ }^{8}$ ).

Citrate is known as one of the ions with highest eluting strength in AEC. ${ }^{31}$ When the second complex was retained for 15.3 minutes even with a mobile phase of $100 \mathrm{mM}$ citrate, it has obviously strong affinity to the stationary phase - thus it cannot be expected to elute at all with a weaker eluting mobile phase like $\mathrm{A}$, in agreement with our observations. Complexes between $\mathrm{Sb}(\mathrm{v})$ and citrate have previously been shown in biological samples, ${ }^{13}$ and the two different complexes must be expected always to coexist. The application of mobile phases with too weak elution strength may thus contribute to the recovery problems experienced when analysing real world samples; therefore, the potential of using mobile phase B with a high elution strength was investigated. Fig. 1 compares the chromatograms achieved with the two mobile phases and shows the most likely nature of the eluted species: When using mobile phase A $\mathrm{Sb}$ (III)-citrate elutes as $\mathrm{Sb}$ (III)-EDTA prior to $\mathrm{Sb}(\mathrm{v})$-citrate. In $100 \mathrm{mM}$ citrate (mobile phase $\mathrm{B}$ ) the elution order of $\mathrm{Sb}(\mathrm{III})$ and $\mathrm{Sb}(\mathrm{v})$ is reversed, which suggests that here $\mathrm{Sb}$ (III) elutes as the actual citrate complex. Like for $\mathrm{Sb}(\mathrm{v})$, the method provides full recovery for $\mathrm{Sb}(\mathrm{III})$.

It should be noted that when $\mathrm{Sb}(\mathrm{v})$ was diluted in water and injected for analysis using mobile phase $\mathrm{B}$, a fraction of Sb eluted in the solvent front presumably unchelated; however, this was avoided by diluting the sample in the mobile phase instead of water (even if it was done immediately prior to analysis). When analysing samples subjected to acid treated using mobile phase $\mathrm{B}$, unchelated $\mathrm{Sb}(\mathrm{v})$ in the solvent front was avoided by including citric acid in the sample treatment mixture or by adding citrate after the acid treatment.

\section{Preservation of oxidation state}

For redox speciation analysis, it is vital that the sample preparation procedure does not change the oxidation state of the species in the sample. As $\mathrm{Sb}(\mathrm{v})$ is the thermodynamically favoured oxidation state in aqueous solution under oxic conditions, ${ }^{32}$ oxidation of $\mathrm{Sb}(\mathrm{III})$ is a risk. $\mathrm{Sb}$ (III)'s oxidation upon acid treatment was explored on a solution of $\mathrm{SbCl}_{3}$ instead of $\mathrm{KSb}$ (III)-tartrate (the normally used standard of $\mathrm{Sb}$ (III)). The chelating ability of tartrate protects against oxidation of $\mathrm{Sb}(\mathrm{III})^{33}$ but cannot be considered representative for conditions in natural samples. A $2 \mu \mathrm{M}$ solution of $\mathrm{SbCl}_{3}$ was prepared with $\mathrm{HCl}(1 \mathrm{M})$ and citric acid $(100 \mathrm{mM})$; after $3 \mathrm{~h}$ a slight oxidation of $\mathrm{Sb}(\mathrm{III})$ was observed (4.9\%). However, addition of $10 \mathrm{mM}$ EDTA decreased the oxidation to $2.3 \%$ and of $30 \mathrm{mM}$ EDTA to $1.7 \%$ (higher EDTA concentrations were not useable due to EDTA precipitation). Based on these results the sample treatment procedure chosen for further experiments was for mobile phase A: $1 \mathrm{M} \mathrm{HCl}$ and $30 \mathrm{mM}$ EDTA, and for mobile phase B: $1 \mathrm{M}$ $\mathrm{HCl}, 100 \mathrm{mM}$ citric acid and $30 \mathrm{mM}$ EDTA.

In spite of the low $\mathrm{pH}$ of the treated samples, direct injection without neutralisation was considered acceptable as the PRP$\mathrm{X} 100$ column has a working range down to $\mathrm{pH} 1$. However, we observed that oxidation was provoked if the acidified samples were repeatedly exposed to the stainless steel injector needle. When injecting only once from each vial the degree of oxidation 
was negligible. Alternatively, the acidic sample can be neutralised prior to injection. However, neutralisation with ammonia, ammonium formate or tetraethylammonium hydroxide was found to cause severe oxidation. In contrast, diammonium hydrogen citrate was found useful as only $2.0 \%$ oxidation was observed $2 \mathrm{~h}$ after neutralisation (performed on an $\mathrm{SbCl}_{3}$ solution incubated $4.5 \mathrm{~h}$ with $1 \mathrm{M} \mathrm{HCl}$ and $10 \mathrm{mM}$ EDTA prior to the neutralisation).

To summarise, as long as the acidic sample's exposure to stainless steel is kept to a minimum, or if neutralisation is done with citrate as base, the oxidation associated with the acidic sample preparation is very limited.

\section{Analysis of ascorbic acid-Sb(v)}

With mobile phase A, the ascorbic acid-Sb(v) mixture displayed poor chromatographic behaviour as obvious from Fig. 2 (I). When the sample was diluted in mobile phase A prior to analysis, a chromatographic recovery of only $45.0( \pm 1.8) \%$ was achieved. If the sample was prepared in $1 \mathrm{M} \mathrm{HCl}$ and $30 \mathrm{mM}$ EDTA the peak shape improved (Fig. 2, II), and so did the recovery, which became $68.6( \pm 1.1) \%$. Some unidentified species render a small peak at 2.2 and 7.4 minutes.

When the ascorbic acid-Sb(v) mixture was diluted in and analysed by means of mobile phase $\mathrm{B}$, the chromatographic recovery was found to be only $41.0( \pm 1.8) \%$ (Fig. 3, I). However, treatment with $1 \mathrm{M} \mathrm{HCl}, 100 \mathrm{mM}$ citrate and $30 \mathrm{mM}$ EDTA rendered a recovery of $71.6( \pm 1.4) \%$ and a much improved peak shape of the main $\mathrm{Sb}(\mathrm{v})$ peak (at $2.2 \mathrm{~min}$ ) (Fig. 3, II). Thus, the recovery of the acid-treated sample was nearly the same for the two mobile phases. However, the shape of the analytical peaks with mobile phase $B$ was much better than with mobile phase $A$, as $\mathrm{B}$ made practically all $\mathrm{Sb}$ elute as peaks of known oxidation state. The increased recovery using both chromatographic methods, after hydrolysis was due to an increase in $\mathrm{Sb}(\mathrm{v})$ solely; hence we conclude that non-eluted $\mathrm{Sb}$ without acid treatment was in the pentavalent oxidation state. The poor chromatography of the ascorbic acid- $\mathrm{Sb}(\mathrm{v})$ mixture and the improvement of recovery and peak shape by $\mathrm{HCl}$ treatment substantiate the theory of $\mathrm{Sb}$ being released from macromolecules after hydrolysis with acid. To test

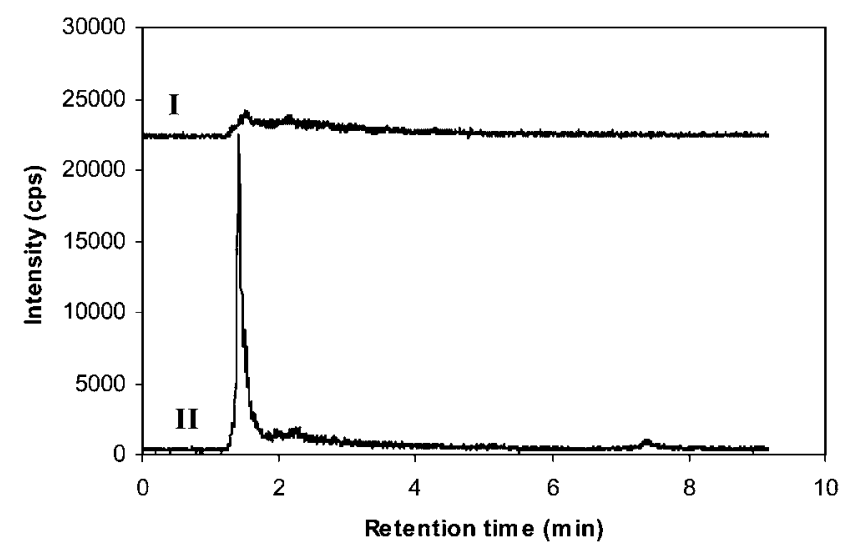

Fig. 2 HPLC-ICP-MS chromatogram of an ascorbic acid-Sb(v) mixture $4 \frac{1}{2} \mathrm{~h}$ after dilution in the mobile phase (I) or after $3 \mathrm{~h}$ treatment with $1 \mathrm{M} \mathrm{HCl}$ and $30 \mathrm{mM}$ EDTA(II). Mobile phase: $20 \mathrm{mM}$ EDTA and $2 \mathrm{mM}$ phthalic acid at $\mathrm{pH} 4.5$ (A).

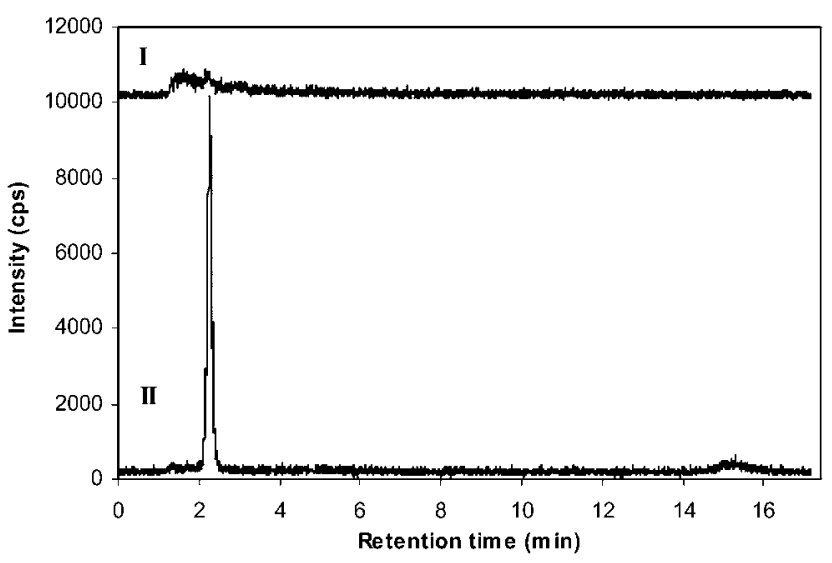

Fig. 3 HPLC-ICP-MS chromatogram of an ascorbic acid-Sb(v) mixture $8 \mathrm{~h}$ after dilution in the mobile phase (I) or after $81 / 2 \mathrm{~h}$ treatment with $1 \mathrm{M} \mathrm{HCl}, 100 \mathrm{mM}$ citric acid and $30 \mathrm{mM}$ EDTA (II). Mobile phase: $100 \mathrm{mM}$ citrate, $\mathrm{pH} 4.5$ (B).

this hypothesis we applied ultrafiltration and field flow fractionation-ICP-MS in order to prove the presence of Sb-containing polymers in the ascorbic acid-Sb(v) mixture.

Ultrafiltration of an ascorbic acid-Sb(v) mixture revealed that $8 \%$ of the total $\mathrm{Sb}$ was bound in macromolecules with a molecular mass above $3 \mathrm{kDa}$. For Pentostam $20 \%$ of the antimony was in a form unable to pass the filter. As a negative control, a solution of $\mathrm{KSb}(\mathrm{OH})_{6}(1.00 \mu \mathrm{M})$ was ultrafiltrated with no decrease in $\mathrm{Sb}$ concentration. These findings are in agreement with previous reports of $\mathrm{Sb}$-containing polymers in Pentostam ${ }^{19,20}$ and suggest that polymers also have been formed in the ascorbic acid-Sb(v) mixture. (The fraction of $\mathrm{Sb}$ in the $\mathrm{Sb}$-ascorbic acid mixture unrecoverable from the HPLC column when not treated with acid is much more than $8 \%$, showing that the unrecoverable $\mathrm{Sb}$ species also include some that are less than $3 \mathrm{kDa}$ molecular weight.)

Analysis of ascorbic acid-Sb(v) and ascorbic acid-Sb(III) mixtures by AFFF-MALS/DLS-ICP-MS showed that $\mathrm{Sb}$ was associated with macromolecules larger than the pores of AFFF bottom membrane ( $3 \mathrm{kDa}$ molecular weight cut-off was used), and only these larger particles would have passed through the AFFF cell to the ICP-MS. The particles did give rise to a single peak corresponding to $\mathrm{Sb}\left({ }^{121} \mathrm{Sb}\right)$ recorded by ICP-MS. The concentration of the complexes was, however, not large enough to generate any useful light scattering signal for direct size determination; hence the particle size was estimated by simulation. The estimated Stokes diameter for the $\mathrm{Sb}(\mathrm{III})$ and $\mathrm{Sb}(\mathrm{v})$ complexes was around $3 \mathrm{~nm}$. Particles of this size would indeed be retained in the carrier liquid inside the AFFF flow cell, as only particles much below $1 \mathrm{~nm}$ in diameter would be lost by passage through the $3 \mathrm{kDa}$ cut-off of the AFFF bottom membrane. The experiments confirmed that Sb-containing macromolecules with a Stokes diameter of approximately $3 \mathrm{~nm}$ were present in the sample solutions, thus confirming and detailing the results obtained by ultracentrifugation.

\section{Analysis of Pentostam}

As stated, Pentostam is known to contain polymers of $\mathrm{Sb}(\mathrm{v})$ and gluconic acid. A sample of Pentostam freshly diluted with mobile 
phase A displayed an ill resolved chromatogram with a recovery of only $26 \%$, using mobile phase A. Upon standing for $3 \frac{1}{2} \mathrm{~h}$ the recovery improved to $81.0( \pm 1.0) \%$, but still the chromatogram contained two unidentified peaks. Sample pretreatment with $1 \mathrm{M}$ $\mathrm{HCl}$ and $30 \mathrm{mM}$ EDTA for approx. $4 \mathrm{~h}$ increased the recovery to $100.5( \pm 0.2) \%$, but a small shoulder on the main $\mathrm{Sb}(\mathrm{v})$ peak was present (ESI, Fig. Si†).

Fig. 4 (I) shows the chromatogram of Pentostam with mobile phase B, diluted $3 \mathrm{~h}$ previously in mobile phase B. At least three unidentified peaks are visible, and the recovery was only $66 \%$. Treatment with $\mathrm{HCl}$ removed the unidentified peaks (Fig. 4, II) and improved the recovery to $98.0( \pm 0.5) \%$. Fig. 4 (I) highlights an advantage of mobile phase $\mathrm{B}$ compared to A, namely that the elution of $\mathrm{Sb}(\mathrm{v})$ is well separated from the solvent front, at 2.2 min as opposed to $1.5 \mathrm{~min}$ (i.e. only $13 \mathrm{~s}$ after the solvent front in our system). Therefore with mobile phase B, unidentified peaks near the solvent front are not likely to be mistaken for the $\mathrm{Sb}(\mathrm{v})$ (potentially leading to false conclusions on the redox speciation of the sample) but are recognised as unknown.

These results show that sample treatment with $\mathrm{HCl}$ significantly improves the recovery for Pentostam with both mobile phases A and B. This may be of interest beyond the level of a model system for biological samples. Franco et al. reported up to $15.4 \%$ of the toxic $\mathrm{Sb}$ (III) in the $\mathrm{Sb}$ (v) drug sodium stibogluconate by titration with iodine combined with differential pulse polarography. ${ }^{34} \mathrm{~A}$ chromatographic method for determination of the redox speciation of this drug could be of significant clinical importance, since it provides a more convenient method for control of $\mathrm{Sb}(\mathrm{v})$ pharmaceutics.

\section{Adenosine-Sb(v) mixture}

In HPLC methods for redox speciation analysis it is desirable to elute all analytes in peaks of known oxidation state. As discussed above, treatment with $\mathrm{HCl}$ and citric acid neatly removed any unidentified peaks in the chromatogram of Pentostam. To explore the removal of unidentified peaks further, a mixture of adenosine and $\mathrm{Sb}(\mathrm{v})$ was analysed. $\mathrm{Sb}(\mathrm{v})$ is known to form complexes with molecules containing a ribose moiety such as ribonucleosides. ${ }^{18}$ Such complexes may potentially be present in $\mathrm{Sb}(\mathrm{v})$-containing biological samples and may not elute with the same retention time

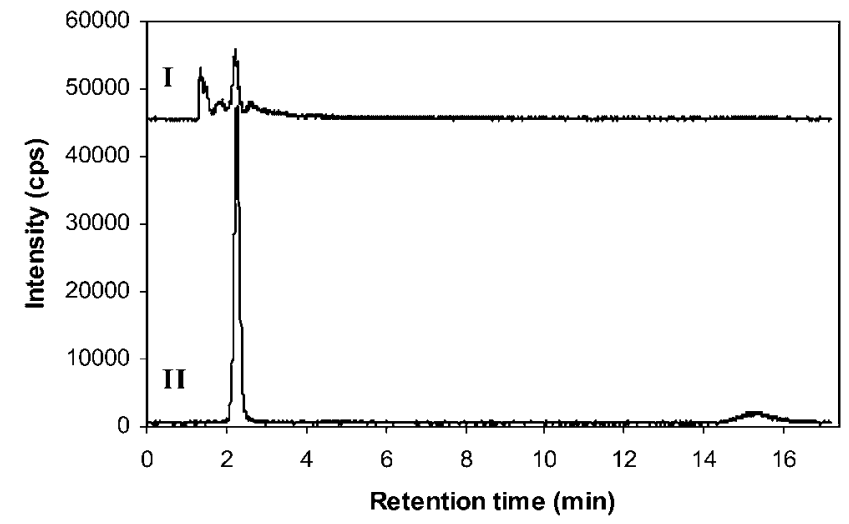

Fig. 4 HPLC-ICP-MS chromatogram of Pentostam $3 \mathrm{~h}$ after dilution in the mobile phase (I) or after $2 \mathrm{~h}$ treatment with $1 \mathrm{M} \mathrm{HCl}, 100 \mathrm{mM}$ citric acid and $30 \mathrm{mM}$ EDTA (II). Mobile phase: $100 \mathrm{mM}$ citrate, $\mathrm{pH} 4.5$ (B). as unbound $\mathrm{Sb}(\mathrm{v})$, potentially leading to unidentified peaks in chromatograms based on mobile phase A. This was the case when analysing a mixture of adenosine and $\mathrm{Sb}(\mathrm{v})$, which showed a broad peak at 5.6 minute besides the normal $\mathrm{Sb}(\mathrm{v})$ peak, when mobile phase A was used. $\mathrm{HCl}$ treatment was not able to remove the unknown peak, which made up $12-14 \%$ of the antimony (ESI, Fig. Sii $\dagger$ ). Next, the chromatographic analysis utilising mobile phase B was tested. When the sample was diluted in mobile phase $\mathrm{B}$ prior to analysis $(2 \mathrm{~h})$ no unknown peaks were visible and the recovery was $82.1( \pm 0.1) \%$. If $\mathrm{HCl}$ treatment was used $(2 \mathrm{~h})$, the recovery increased to $97.5( \pm 1.1) \%$ (ESI, Fig. Siii $\dagger$ ). Thus, the latter procedure was preferable.

\section{Cell extract}

It has so far been demonstrated that $\mathrm{HCl}$ treatment and the use of mobile phase B greatly improve the chromatography of the simulated biological samples. To test if this also holds true for a real biological sample, we analysed an extract of human leukocyte cells grown in medium with Pentostam added. The chromatogram of the cell extract analysed with mobile phase A had a chromatographic recovery of $66.0( \pm 2.0) \%$ and displayed an unidentified peak immediately after (and incompletely resolved from) the $\mathrm{Sb}(\mathrm{v})$ peak (ESI, Fig. Siv, $\mathrm{I} \dagger$ ).

With mobile phase $\mathrm{B}$ the cell extract had a chromatographic recovery of $77.4( \pm 2.2) \%$ (Fig. 5, I). The recovery was determined ca. 2 and $6 \mathrm{~h}$ after dilution in mobile phase $\mathrm{B}$ and did not increase during this time span. The chromatogram showed baseline resolution, but there was an unidentified peak at the solvent front (1.4 minute). Treatment with $\mathrm{HCl}$ increased the recovery to 96.7 $( \pm 1.6) \%$ (whether the treatment was for 1,2 or $4 \mathrm{~h}$ had no obvious influence). The chromatogram did not contain any unknown peaks (Fig. 5, II). It is interesting to note that the eluted amount of $\mathrm{Sb}$ (III) relative to the total amount of $\mathrm{Sb}$ (determined by direct injection) is the same before and after the acid treatment; $31.1( \pm 1.3) \%$ before $(n=3)$ vs. $30.9( \pm 0.9) \%$ after $(n=6)$. This suggests that the $\mathrm{Sb}$ not eluted of the column, thereby causing incomplete recovery before acid treatment, is in the pentavalent oxidation state. It also confirms that the acid treatment causes no significant oxidation of $\mathrm{Sb}(\mathrm{III})$ in the sample.

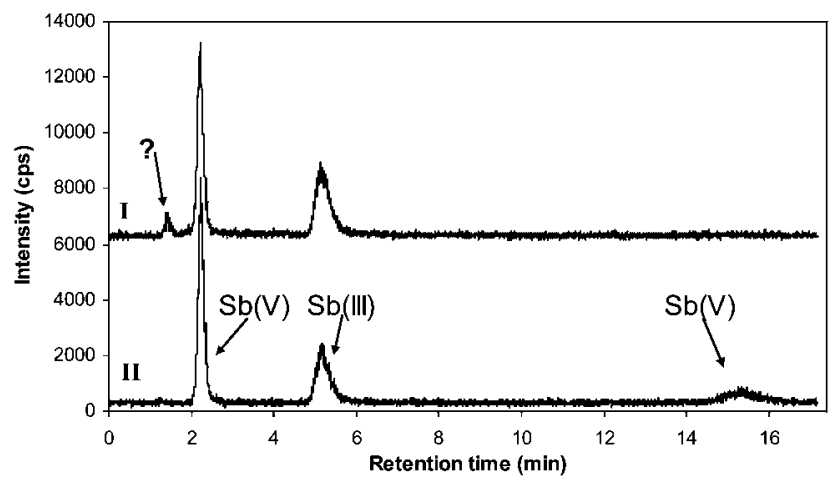

Fig. 5 HPLC-ICP-MS chromatogram of a cell extract diluted in the mobile phase (6 h after dilution, I); or treated with $1 \mathrm{M} \mathrm{HCl}$ and $100 \mathrm{mM}$ citrate for $2 \mathrm{~h}$ (II). Mobile phase: $100 \mathrm{mM}$ citrate, pH 4.5 (B). ( $\mathrm{Sb}$ (v) elutes in two peaks as discussed in the section on optimisation of the chromatographic method.) 


\section{Conclusion}

Our experiments strongly indicate the formation of polymers between $\mathrm{Sb}$ and biological molecules in dilute solutions, and that these corrupt the chromatographic HPLC recoveries of such samples. Treatment with $1 \mathrm{M} \mathrm{HCl}$ greatly improved the recovery and shape of chromatograms of both simulated and real biological samples. In all samples it was $\mathrm{Sb}(\mathrm{v})$ that was recovered. As $\mathrm{Sb}$ (III) is stable/not oxidised during our methodology it can be concluded that the macromolecules causing low recoveries contained $\mathrm{Sb}(\mathrm{v})$. Likewise, replacement of the classical EDTA/ phthalic acid mobile phase (A) with citrate (B) improves peak shape and chromatographic recovery. Citrate will ensure high elution strength, avoiding compounds sticking permanently to the column material. At the same time, excess citrate will substitute ligands otherwise binding to antimony, resulting in chromatograms with a maximum of three antimony peaks (one for $\mathrm{Sb}(\mathrm{III})$ and two for $\mathrm{Sb}(\mathrm{v}))$. In the case of Pentostam, acid treatment alone gave full recovery even with mobile phase A, so for relatively simple matrices the acid treatment alone may be sufficient for achieving a satisfactory chromatography. In conclusion, our goal of developing an improved method for $\mathrm{Sb}$ redox speciation analysis in biological samples was achieved.

\section{References}

1 World Health Organization, Antimony in Drinking-Water, WHO/ SDE/WSH/03.04/74, Geneva, 2003.

2 H. R. Hansen and S. A. Pergantis, J. Anal. At. Spectrom., 2008, 23, 1328-1340.

3 R. Miravet, E. Hernéndez-Nataren, A. Sahuquillo, R. Rubio and J. F. López-Sánchez, TrAC, Trends Anal. Chem., 2010, 29, 28-39.

4 J. Lintschinger, I. Koch, S. Serves, J. Feldmann and W. R. Cullen, Fresenius J. Anal. Chem., 1997, 359, 484-491.

5 M. Krachler, H. Emons and J. Zheng, TrAC, Trends Anal. Chem., 2001, 20, 79-90.

6 H. R. Hansen and S. A. Pergantis, Anal. Chem., 2007, 79, 5304-5311.

7 S. Wehmeier, A. Raab and J. Feldmann, Appl. Organomet. Chem., 2004, 18, 631-639.

8 H. R. Hansen and S. A. Pergantis, J. Anal. At. Spectrom., 2006, 21, $1240-1248$.

9 J. Zheng, A. Iijima and N. Furuta, J. Anal. At. Spectrom., 2001, 16, 812-818.

10 S. Canepari, E. Marconi, M. L. Astolfi and C. Perrino, Anal. Bioanal. Chem., 2010, 397, 2533-2542.
11 S. Foster, W. Maher, F. Krikowa, K. Telford and M. Ellwood, J. Environ. Monit., 2005, 7, 1214-1219.

12 N. Miekeley, S. R. Mortari and A. O. Schubach, Anal. Bioanal. Chem., 2002, 372, 495-502.

13 H. R. Hansen and S. A. Pergantis, J. Anal. At. Spectrom., 2006, 21, 731-733.

14 M. Krachler and H. Emons, J. Anal. At. Spectrom., 2001, 16, 20-25.

15 I. de Gregori, W. Quiroz, H. Pinochet, F. Pannier and M. PotinGautier, Talanta, 2007, 73, 458-465.

16 A. Guy, P. Jones and S. J. Hill, Analyst, 1998, 123, 1513-1518.

17 C. C. Cumbo and P. C. Yates, US Pat., 3873451, 1975.

18 H. R. Hansen and S. A. Pergantis, Anal. Bioanal. Chem., 2006, 385, 821-833.

19 H. R. Hansen, C. Hansen, K. P. Jensen, S. H. Hansen, S. Stürup and B. Gammelgaard, Anal. Chem., 2008, 80, 5993-6000.

20 F. Frézard, P. S. Martins, M. C. Barbosa, A. M. Pimenta, W. A. Ferreira, J. E. de Melo, J. B. Mangrum and C. Demicheli, J. Inorg. Biochem., 2008, 102, 656-665.

21 C. E. Carraher, Jr, in Inorganic and Organometallic Macromolecules: Design and Applications, ed. A. S. Abd-El-Aziz, C. E. Carraher, C. U. J. Pittman and M. Zeldin, Springer, New York, 2008, pp. 405-419.

22 C. E. Carraher, Jr and H. S. Blaxall, Angew. Makromol. Chem., 1979, 83, 37-45.

23 D. M. Chay, C. C. Cumbo, M. J. Randolph and P. C. Yates, US Pat., $3676477,1972$.

24 J. H. Saunders and F. Dobinson, in Non-Radical Polymerisation, ed. C. H. Bamford and C. F. H. Tipper, Elsevier Scientific Publishing Company, Amsterdam, 1976, vol. 15, ch. 7, pp. 473-581.

25 A. Ledwith and D. C. Sherrington, in Non-Radical Polymerisation, ed. C. H. Bamford and C. F. H. Tipper, Elsevier Scientific Publishing Company, Amsterdam, 1976, vol. 15, ch. 2, pp. 67-131.

26 F. A. El-Toufaili, G. Feix and K. H. Reichert, J. Polym. Sci., Part A: Polym. Chem., 2006, 44, 1049-1059.

27 A. Schulz, C. Trage, H. Schwarz and L. W. Kroh, Int. J. Mass Spectrom., 2007, 262, 169-173.

28 É. M. de Flores, E. P. dos Santos, J. S. Barin, R. Zanella, V. L. Dressler and C. F. Bittencourt, J. Anal. At. Spectrom., 2002, 17, 819-823.

29 L. Moesby, E. W. Hansen, J. D. Christensen, C. H. Høyer, G. L. Juhl and H. B. Olsen, Eur. J. Pharm. Sci., 2005, 26, 318-323.

30 V. S. Santos, W. d. R. Santos, L. T. Kubota and C. R. T. Tarley, J. Pharm. Biomed. Anal., 2009, 50, 151-157.

31 J. M. Miller, Chromatography: Concepts and Contrasts, John Wiley \& Sons, Inc., Hoboken, New Jersey, 2nd edn, 2005, ch. 8, pp. 183-276.

32 M. Filella and P. M. May, Geochim. Cosmochim. Acta, 2003, 67, 4013-4031.

33 M. Filella, N. Belzile and Y.-W. Chen, Earth-Sci. Rev., 2002, 59, 265285.

34 M. A. Franco, A. C. Barbosa, S. Rath and J. G. Dorea, Am. J. Trop. Med. Hyg., 1995, 52, 435-437. 